\title{
O papel do Governo Eletrônico no fortalecimento da governança do setor público
}

\author{
Lamartine Vieira Braga, Welington Souza Alves, \\ Rejane Maria da Costa Figueiredo e Rildo Ribeiro dos Santos
}

\section{Introdução}

A administração pública chega a este novo milênio com a tarefa de se ajustar a um mundo em constante mudança, no qual se exige dos governantes maior eficiência estatal aliada a um rol crescente de serviços públicos, com maior qualidade, controle social e garantia dos direitos individuais.

As novas Tecnologias da Informação e Comunicação (TIC), entre as quais se destacam a internet, as redes de computadores, a transmissão via satélite e a telefonia móvel, criaram condições para o surgimento de sociedades do conhecimento. Em tal conjuntura, o Estado, por intermédio do governo eletrônico, é o principal instrumento de que os cidadãos dispõem atualmente para enfrentar os desafios impostos pela globalização, por meio de interações inéditas da sociedade, empresas e governos. Nesse ambiente, os valores que dizem respeito à governança são fundamentais. 
O objetivo deste artigo é ilustrar o avanço da governança em nosso País, com base nas iniciativas aqui inventariadas no campo do governo eletrônico. Assim, foi adotada a seguinte metodologia: procedeuse à pesquisa bibliográfica sobre as definições mais relevantes nessas áreas e realizou-se uma análise de dois portais do Governo Federal brasileiro na internet, além de outras ações do Governo Eletrônico brasileiro.

O presente documento está organizado da seguinte forma: nas seções 2 e 3, expõem-se os conceitos de governança no setor público e governo eletrônico. $\mathrm{Na}$ seção 4, mostram-se alguns casos do governo eletrônico que dão suporte à governança do setor público brasileiro, iniciando por um breve histórico. São analisadas, na seqüência, ações do Governo Eletrônico brasileiro à luz das definições previamente examinadas, bem como suas correlações de impacto sobre a governança do setor público. Ao final, na seção 5, são tecidas as considerações finais.

\section{Governança no Setor Público}

De acordo com a Organização para Cooperação e Desenvolvimento Econômico - OCDE (2005), a governança precisa adaptar-se continuamente em resposta a pressões como extensão do comércio nacional e internacional; mudança de poderes entre níveis de governo; difusão de novas tecnologias e mídia de massa; permeabilidade das fronteiras nacionais; influência de comunidades globalizadas de valores e interesses; e vulnerabilidade das sociedades face ao terrorismo. Cabe, ainda, destacar as dificuldades inerentes à medição da governança, independentemente dos dados utilizados (Kaufmann; KraAy; MastruzZi, 2007).
Governança se refere aos arranjos formais e informais que determinam como as decisões políticas são postas em prática, da perspectiva da manutenção dos valores constitucionais de um país frente a problemas, atores e ambiente em mudança. Nesse conjunto de circunstâncias, a administração pública é um pilar constituinte da governança (OCDE, 2005).

A OCDE (2005) identifica nove elementos centrais de governança, listados a seguir: democracia e cidadania; representação; uma constituição; a regra da lei; partidos competitivos e sistemas eleitorais; serviço público permanente; separação de poderes; revisão judiciária; e secularidade. Embora os países façam uso de elementos comuns, estes são dispostos de diferentes formas e estão em constante fluxo.

Idéias de boa governança emergem de presunções sobre a condição dos direitos individuais de propriedade; inviolabilidade; igualdade; compensação dentro da lei; e participação em tomada de decisão coletiva (OcDe, 2005).

Os autores Shah e Shah (2006), discorrendo sobre governos locais e governança, afirmam que esta última não se limita à provisão de uma gama de serviços, mas também se estende à preservação da vida e da liberdade dos residentes; criação de espaço para participação democrática e diálogo cívico; apoio ao mercado e ao desenvolvimento sustentável; e facilitação de resultados que enriqueçam a qualidade de vida dos residentes.

Em relatório sobre reforma do setor público, o Banco Mundial (2000) arrola três mecanismos promotores da boa governança:

- Regras internas e restrições: sistemas internos de auditoria e responsabilização; independência do Poder Judiciário e do Banco Central; normas aplicadas ao 
serviço público e ao orçamento; e regulamentação sobre órgãos de controle externo;

- Voz e parceria: descentralização com vistas a empoderar comunidades; pesquisas de retorno aos clientes sobre a oferta de serviços; e relatórios e comentários tratando da elaboração de regramento regulatório; e

- Competição: disponibilização competitiva de serviços sociais; participação privada na infra-estrutura; mecanismos alternativos de resolução de disputas; e privatização de certas atividades orientadas ao mercado.

Os dois últimos mecanismos podem, adicionalmente, aumentar a transparência e a responsabilização governamental.

Os princípios de governança do serviço público australiano (2007) são os seguintes: responsabilização; transparência; integridade; representação; eficiência; e liderança.

A Comissão Independente sobre Governança nos Serviços Públicos do Reino Unido (2004) estabeleceu seis princípios centrais de boa governança, elencados a seguir: foco no objetivo organizacional e nos resultados para os cidadãos e usuários dos serviços; desempenho efetivo em funções e papéis claramente definidos; promoção de valores para a organização como um todo e demonstração dos valores de boa governança por meio do comportamento; provisão de informações, decisões transparentes e gestão do risco; desenvolvimento da capacidade e da habilidade do corpo de governo em ser efetivo; e engajamento dos grupos interessados e concretização da responsabilização.

Segundo Kaufmann, Kraay e Mastruzzi (2007), a governança pode ser agrupada em seis dimensões que refletem uma metodologia de agregação de centenas de variáveis individuais e específicas, aferindo suas diversas percepções:

- Voz e responsabilização: mede a extensão em que os cidadãos estão aptos a participar na escolha de seu governo, assim como a liberdade de expressão, a liberdade de associação e a liberdade dos meios de comunicação;

- Estabilidade política e ausência de violência: mede as percepções de probabilidade de que o governo venha a

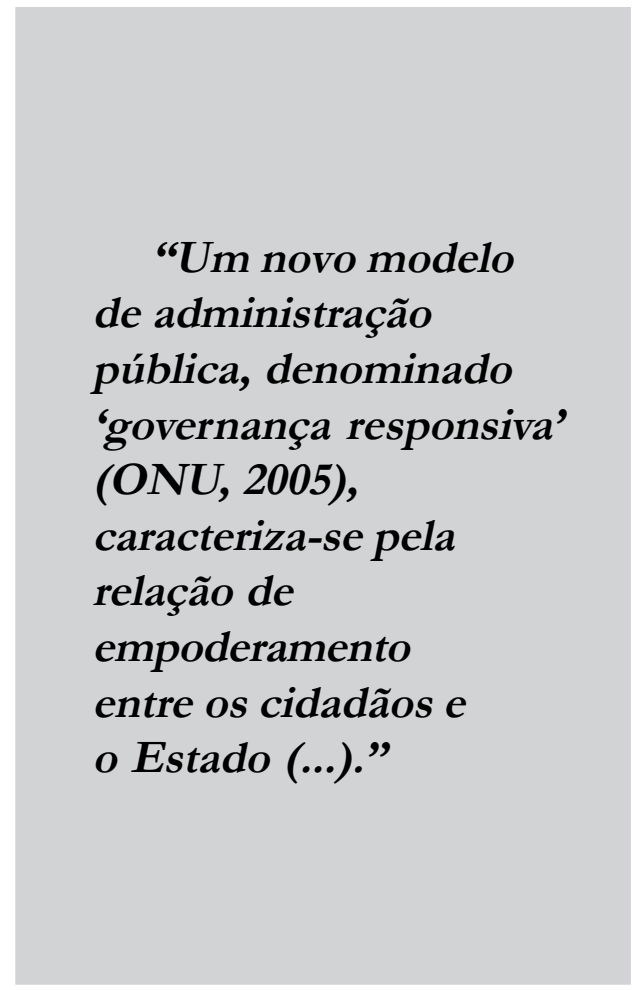

ser desestabilizado ou deposto por meios violentos ou inconstitucionais, inclusive domésticos, e também por terrorismo;

- Efetividade governamental: mede a qualidade dos serviços e dos servidores públicos e o grau de independência a pressões políticas; a qualidade da formulação e implementação de políticas públicas; e a credibilidade quanto ao comprometimento dos governos frente a essas políticas; 
- Qualidade regulatória: mede a habilidade dos governos em formular e implementar regulação e políticas públicas seguras que permitam e promovam o desenvolvimento do setor privado;

- Regra da lei: mede o grau em que os agentes têm confiança e se submetem a agir de acordo com as regras da sociedade, ou seja, a observância dos contratos, a propensão ao crime e à violência e a atuação da polícia e dos tribunais; e

- Controle da corrupção: mede a extensão em que o Poder Público é exercido em proveito próprio, para obtenção de benefícios privados, incluindo tanto pequenas quanto grandes formas de corrupção e a captura do Estado pelas elites e interesses particulares.

A Figura 1 apresenta uma hierarquia de valores entre as atividades do dia-a-dia (governo responsivo) e os valores compartilhados que dão suporte a constituições e mantêm sociedades unidas no longo prazo (governo legítimo).

Quando se discutem questões de governança, como em outras áreas de execução de políticas públicas, uma ação tomada para resolver um problema de curto ou médio prazo pode ter efeitos de longo prazo na legitimidade de um governo. Por exemplo, a ocorrência de falhas no atendimento das demandas da sociedade no curto prazo (responsividade) pode acarretar conseqüências na significância da governança no longo prazo, abalando sua legitimidade. Não há uma clara linha divisória entre administração pública e governança: qualquer mudança governamental significativa pode afetá-la.

Um novo modelo de administração pública, denominado de "governança responsiva" (OrganiZAÇÃO DAS NAÇÕES UNIDAS, 2005), caracteriza-se pela relação de empoderamento entre os cidadãos e o
Estado; seus princípios orientadores são a responsabilização, a transparência e a participação; e o atributo-chave é a responsividade (Figura 1).

Este paradigma inovador desponta em paralelo com formas inéditas de pensar e agir, apoiadas nas modernas TIC, tornando possível um processo de decisão mais informado e transparente. Além disso, o uso dessas tecnologias permite uma interface governo-cidadão de mão dupla, via sistemas de comunicação eletrônica e transações seguras no fornecimento de serviços e integração interorganizacional, possibilitando ao usuário resolver múltiplos problemas em um único ponto de acesso virtual, com implicações na responsividade e responsabilização governamentais.

\section{Governo Eletrônico}

Relatório da Organização das Nações Unidas (2002) sobre o assunto governo eletrônico, de forma ampla, inclui virtualmente todas as aplicações e plataformas de TIC usadas no setor público. De forma mais restrita, refere-se ao "uso da internet e da Web para disponibilizar informação e serviços aos cidadãos".

Para a OCDE (2003), governo eletrônico é definido como o uso das TIC, em particular a internet, como ferramenta para levar a um melhor governo.

De acordo com a Comunidade Européia (2003), governo eletrônico relaciona-se ao uso das TIC na administração pública combinado com mudança organizacional e novas práticas, a fim de melhorar os serviços públicos, os processos democráticos e fortalecer o suporte às políticas públicas.

O órgão responsável pelo controle externo no Reino Unido atribui ao governo eletrônico o significado de prover, 
via internet, acesso público a informações sobre todos os serviços oferecidos pelos departamentos centrais de governo e suas agências e de possibilitar ao público a condução e a conclusão de transações relativas a todos esses serviços (NAtional Audit OFFICE, 2002). cidadão, diminuindo a arbitrariedade do Estado e contribuindo para o progresso da democracia.

O autor supracitado, ao analisar a doutrina inglesa, verifica a aplicação dos métodos do comércio eletrônico ao serviço público e inventaria os seguintes

\begin{tabular}{|c|c|c|}
\hline & Governo responsivo & \\
\hline \multirow[t]{11}{*}{$\begin{array}{l}\text { Significância da } \\
\text { governança no curto } \\
\text { prazo }\end{array}$} & $\begin{array}{l}\text { - Executa fielmente as políticas do dia a dia. } \\
\text { - Satisfaz as necessidades dos grupos de cli- } \\
\text { entes. }\end{array}$ & $\begin{array}{l}\text { - Políticas atuais satisfazem as } \\
\text { necessidades dos cidadãos envolvidos. }\end{array}$ \\
\hline & - Comunica-se e toma conselhos. & \\
\hline & Governo responsável & \\
\hline & $\begin{array}{l}\text { - Serve aos interesses de todos os cidadãos, } \\
\text { prestando atenção no impacto das políticas } \\
\text { de longo prazo. }\end{array}$ & - Cuida dos interesses coletivos. \\
\hline & - Não sobrecarregará futuras gerações. & \\
\hline & $\begin{array}{l}\text { - Adaptativo - toma decisões firmes envol- } \\
\text { vendo recursos e a organização quando ne- } \\
\text { cessário. }\end{array}$ & \\
\hline & $\begin{array}{l}\text { - Interesse coletivo protegido de ganhos } \\
\text { privados. }\end{array}$ & \\
\hline & Governo legítimo & \\
\hline & $\begin{array}{l}\text { - Constituição e leis duradouras em espírito } \\
\text { e ações. }\end{array}$ & $\begin{array}{l}\text { - Constrói e mantém a confiança } \\
\text { nas instituições públicas. }\end{array}$ \\
\hline & $\begin{array}{l}\text { - Trata cidadãos imparcialmente, respeita } \\
\text { os indivíduos e a comunidade. Senso de segu- } \\
\text { rança mantido. }\end{array}$ & \\
\hline & - Tomada de decisões transparente. & \\
\hline \multirow{2}{*}{$\begin{array}{l}\text { Significância da } \\
\text { governança no longo } \\
\text { prazo }\end{array}$} & - Uso do poder coercivo. & \\
\hline & $\begin{array}{l}\text { - Interesse coletivo protegido de ganhos } \\
\text { privados. }\end{array}$ & \\
\hline
\end{tabular}

Figura 1: Hierarquia de Valores (Fonte: Adap. da OCDE, 2005)

Pierre Lévy (2004) afirma que as iniciativas relacionadas ao governo eletrônico atuam no sentido de simplificar os procedimentos administrativos; tornar os processos de produção legislativa mais transparentes; aproximar o governo do cidadão pela via da internet; e melhorar a eficácia, a eficiência e a competitividade da administração pública.

Isso implica, além da redução dos níveis hierárquicos, centrar o governo no princípios fundamentais do governo eletrônico:

- Construir os serviços em torno das escolhas dos cidadãos (e não dentro das portas fechadas da administração);

- Tornar o Estado e os seus serviços mais acessíveis (especialmente pela internet);

- Incluir as populações desfavorecidas pelas formas tradicionais de governo (serviços para as minorias lingüísticas, os deficientes, os expatriados, os estrangeiros); 
- Utilizar de forma melhor a informação (em particular, graças à integração de sistemas de informação atualmente segregados).

Entre os benefícios advindos da nova forma de relação Estado-sociedade, destacam-se: interatividade; eficiência; maior acesso aos serviços públicos, com incremento da qualidade (simplicidade, rapidez); aumento da participação popular; fomento à transparência; incentivo ao controle social; fortalecimento da governança; redução de custos; promoção da cooperação interorganizacional do Estado; organização das informações dos órgãos do governo; e segurança da informação.

\section{Governo Eletrônico como} suporte à governança do setor público - análise da realidade brasileira

\section{Breve histórico do Governo Eletrônico no Brasil}

Em dezembro de 1999, foi instituído no Brasil o Programa Sociedade da Informação ${ }^{1}$, com o objetivo de viabilizar a nova geração da internet e suas aplicações em benefício da sociedade brasileira (BRASIL, 2000).

No ano de 2000, foi criado o Comitê Executivo de Governo Eletrônico ${ }^{2}$, com o objetivo de formular políticas, estabelecer diretrizes, coordenar e articular as ações de implantação do Governo Eletrônico, voltado para a prestação de serviços e informações ao cidadão. O Ministério do Planejamento, Orçamento e Gestão exerce as atribuições de Secretaria-Executiva do comitê, fornecendo apoio técnico-administrativo necessário ao seu funcionamento.

Em 2001, aconteceu o lançamento da Política de Governo Eletrônico no Brasil ${ }^{3}$, com as seguintes linhas de ação:
- Oferta na internet de todos os serviços prestados ao cidadão, com melhoria dos padrões de atendimento, redução de custos e facilidade de acesso;

- Ampliação do acesso a informações pelo cidadão, em formatos adequados, por meio da internet;

- Promoção da convergência entre sistemas de informação, redes e bancos de dados governamentais para permitir o intercâmbio de informações e a agilização de procedimentos;

- Implantação de uma infra-estrutura avançada de comunicações e de serviços, com padrões adequados de segurança e serviços, além de alto desempenho;

- Utilização do poder de compra do Governo Federal para a obtenção de custos menores e a otimização do uso de redes de comunicação;

- Estimulação do acesso à internet, em especial por meio de pontos de acesso abrigados em instituições públicas ou comunitárias; e

- Concorrência para o fortalecimento da competitividade sistêmica da economia.

No ano de 2003, a Presidência da República publicou um decreto ${ }^{4}$ instituindo oito Comitês Técnicos de Governo Eletrônico.

Ainda naquele ano, foi instituído o Sistema Brasileiro de Televisão Digital SBTVD $^{5}$, cujo primeiro objetivo é promover a inclusão social, a diversidade cultural do País e a língua pátria por meio do acesso à tecnologia digital, visando à democratização da informação.

No ano de 2006, foi publicado o decreto $^{6}$ que dispõe sobre a implantação do Sistema Brasileiro de Televisão Digital Terrestre - SBTVD-T, estabelecendo diretrizes para a transição do sistema de transmissão analógica para o sistema de transmissão digital do serviço de 
radiodifusão de sons e imagens e do serviço de retransmissão de televisão.

\section{Ações Promotoras da Governança do Setor Público}

Nesta subseção são examinadas ações do Governo Federal brasileiro, procurando-se determinar a conexão com as várias dimensões da governança no setor público conceituadas anteriormente. As ações avaliadas são as seguintes: certificação digital; Portal da Transparência; votação eletrônica; pregões eletrônicos e Portal da Previdência Social. Além disso, analisamse as implicações da inclusão digital sobre as demais ações previamente observadas.

A certificação digital pode ser definida como "atividade de reconhecimento em meio eletrônico que se caracteriza pelo estabelecimento de uma relação única, exclusiva e intransferível entre uma chave de criptografia e uma pessoa física, jurídica, máquina ou aplicação. Esse reconhecimento é inserido em um Certificado Digital, por uma Autoridade Certificadora" (BRASIL, 2007a).

Autoridade Certificadora, por sua vez, é a entidade subordinada à hierarquia da infra-estrutura de chaves públicas responsável por emitir, distribuir, renovar, revogar e gerenciar certificados digitais (BRASIL, 2007a).

Infra-estrutura de chaves públicas conceitua-se como o conjunto de técnicas, arquitetura, organização, práticas e procedimentos, implementados pelas organizações governamentais e privadas que suportam, em conjunto, a implementação e a operação de um sistema de certificação. Tem como objetivo estabelecer os fundamentos técnicos e metodológicos de um sistema de certificação digital baseado em criptografia de chave pública (BRASIL, 2007a).
No ano de 2001, foi instituída a InfraEstrutura de Chaves Públicas Brasileira (ICP-BRASIL) ${ }^{7}$, com a finalidade de garantir a autenticidade, a integridade e a validade jurídica de documentos em forma eletrônica, das aplicações de suporte e das aplicações habilitadas que utilizem certificados digitais, bem como a realização de transações eletrônicas seguras.

No Brasil, o Instituto Nacional de Tecnologia da Informação (ITI) é a

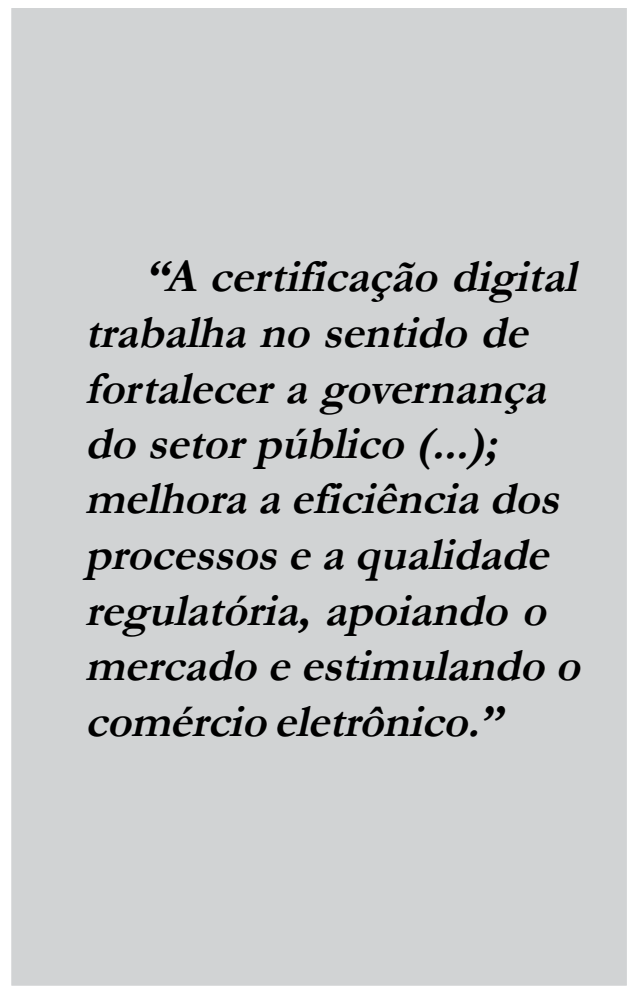

Autoridade Certificadora Raiz da ICP-BRASIL, ou seja, a primeira autoridade da cadeia de certificação, executora das políticas de certificados e de normas técnicas e operacionais aprovadas pelo Comitê Gestor da ICP-Brasil.

Atualmente, existe uma série de serviços que usam aplicações da certificação digital por intermédio da ICP-BRASIL, entre os quais se destacam: 
- Sistema de Pagamentos Brasileiro $\mathrm{SPB}$ - responsável pelo gerenciamento do processo de compensação e liqüidação de pagamentos por meio eletrônico, ligando as instituições financeiras credenciadas ao Banco Central do Brasil;

- Tramitação e assinatura eletrônica de documentos oficiais, por ministros e pelo presidente da República, para publicação no Diário Oficial da União;

- Registro de operações e prestações do ICMS pela internet - Nota Fiscal Eletrônica - em diversos estados da Federação;

- Registro de operações e prestações de impostos federais pela internet;

- Consulta da situação dos contribuintes na base da Receita Federal;

- Assinatura de contratos de câmbio e apólices de seguros;

- Programas de governo, como o Universidade para Todos, do Ministério da Educação, e o Conectividade Social, da Caixa Econômica Federal;

- Pregões Eletrônicos e Portal de Compras do Governo Federal - Comprasnet;

- Sistemas estruturadores do Governo Federal;

- Internet banking e mobile banking;

- Automação de processos do Poder Judiciário;

- Acesso ao Sistema de Comércio Exterior - Siscomex.

A certificação digital trabalha no sentido de fortalecer a governança do setor público, principalmente pelo ato de assegurar a inviolabilidade de informações do cidadão, contribuindo para a consolidação da cidadania. Adicionalmente, a atividade também melhora a eficiência dos processos e a qualidade regulatória, apoiando o mercado e estimulando o comércio eletrônico.

A Controladoria-Geral da União (CGU), órgão subordinado à Presidência da República, criou, em 2004, o Portal da Transparência ${ }^{8}$, canal pelo qual o cidadão pode acompanhar e fiscalizar a execução financeira dos programas governamentais, possibilitando o controle social. Nele encontram-se informações sobre os recursos públicos transferidos pelo Governo Federal a estados, municípios e ao Distrito Federal, assim como dados sobre os gastos realizados em compras e contratações de obras e serviços.

O Portal da Transparência dispõe, atualmente, de dois tipos de consultas:

- Aplicações diretas: informações sobre os gastos diretos do Governo Federal em compras ou contratação de obras e serviços. A pesquisa pode ser feita por órgão ou por tipo de despesa, como diárias, material de expediente, compra de equipamentos, obras e serviços. Podem, ainda, ser consultados os gastos realizados por meio de cartões de pagamentos do Governo Federal.

- Transferências de recursos: informações sobre como é feita a transferência dos recursos federais a estados, municípios, Distrito Federal e direto ao cidadão. É possível consultar a distribuição de recursos de programas como o Bolsa Família e a aplicação de recursos do Sistema Único de Saúde, entre outros.

Os dados são de responsabilidade dos ministérios, que são os executores dos programas de governo. A CGU, por sua vez, reúne e disponibiliza as informações sobre a aplicação dos recursos no portal. Sua atualização é feita mensalmente com a inserção de dados sobre a execução financeira dos programas e ações do Governo Federal. Os dados que o alimentam são oriundos do Fundo Nacional de Saúde, da Caixa Econômica Federal, da Secretaria do Tesouro Nacional e do Banco do Brasil. 
Tal ação apóia diretamente a governança do setor público, pelo aumento da transparência. A conseqüência da provisão de informações, além de incentivar o controle social, tornar as decisões inequívocas e assegurar a correta aplicação dos recursos públicos, é o controle da corrupção, a responsabilização dos gestores e a consolidação da cidadania.

Em 1996, teve início a informatização do voto nas eleições municipais. Cerca de 33 milhões de eleitores usaram as urnas eletrônicas naquele ano. $\mathrm{Na}$ eleição geral de 1998, o voto informatizado alcançou cerca de 75 milhões de eleitores. No ano 2000 , todos puderam utilizar o novo processo para eleger prefeitos e vereadores. $\mathrm{Na}$ eleição municipal de 2004, a votação eletrônica alcançou todos os municípios brasileiros, sendo usada por 119.782.000 eleitores, em um universo de 182 milhões de pessoas. No total, foram utilizadas 408.810 urnas. A totalização dos resultados foi divulgada em menos de 24 horas do encerramento do processo de votação (NAZARENo et al., 2007).

O ano de 2006 caracterizou-se por várias iniciativas da Justiça Eleitoral no sentido de modernizar e aprimorar tanto a instituição quanto o processo eleitoral, culminando na realização das eleições para os cargos de presidente da República, vicepresidente, governador, vice-governador, senador, deputado federal, deputado estadual e deputado distrital. A velocidade da totalização dos votos obtida no pleito em questão deveu-se ao aprimoramento do processo eletrônico. Naquela ocasião, o Tribunal Superior Eleitoral (TSE) bateu o recorde histórico, alcançando, no segundo turno, a totalização de 90\% dos votos às $19 \mathrm{~h}$ do dia da eleição. Às $21 \mathrm{~h} 15$, já haviam sido apuradas 99\% das urnas (BRAsIL, 2007).
A campanha Vota Brasil, das eleições de 2006, visou tanto a estimular os eleitores a votar como a esclarecer a importância do exercício da cidadania. A abstenção nos dois turnos foi inferior à das eleições de 2002. É de ressaltar também o modelo de divulgação de resultados, diretamente por meio da página do TSE, mecanismo que ensejou, pela primeira vez, o acompanhamento, em tempo real, das apurações para os cargos de presidente da República e governador (BRASIL, 2007).

A contribuição da votação eletrônica para o reforço da governança do setor público dá-se pela solidificação da democracia, da cidadania, da igualdade, da voz e da representação; de forma complementar, pelos ganhos de eficiência e transparência em todo o processo.

No ano de 2002, foi instituída no Brasil uma nova modalidade de licitação denominada pregão ${ }^{9}$, destinada à aquisição de bens e serviços comuns para a administração pública, cujos padrões de desempenho e qualidade possam estar objetivamente definidos em um edital, com a adoção de especificações de uso corrente.

O pregão busca incrementar a competitividade e a agilidade nas contratações públicas, com a desburocratização dos procedimentos e a diminuição de custos, e vem-se consolidando como a principal forma de contratação do Governo Federal.

Posteriormente, em 2005, tornou-se obrigatório o uso do pregão eletrônico para aquisição de bens e serviços comuns, salvo nos casos de comprovada inviabilidade, a ser justificada pela autoridade competente $^{10}$.

A aplicação dessa ferramenta permite, entre outras vantagens, a utilização de novas TIC, com seus variados recursos, notadamente o uso da internet. Por intermédio do Comprasnet ${ }^{11}$, é possível acessar uma 
série de funcionalidades do pregão eletrônico: vincular equipe de pregão; operar e visualizar propostas; aceitar, habilitar, fechar e reabrir prazo de intenção de recursos; emitir juízo de admissibilidade; encerrar sessão; decidir recursos; adjudicar o objeto; visualizar ata e proposta; suspender e reabrir pregão; acompanhar recursos; incluir impugnações, esclarecimentos e avisos; cancelar, homologar, revogar e anular pregão.

A governança do setor público se favorece pela ação modernizadora, porquanto promotora do incremento da eficiência, via automação de sistemas e processos administrativos. Além disso, apóia o mercado, por gerar competitividade entre os fornecedores, permitindo, inclusive, a participação de médias e pequenas empresas nas licitações promovidas pelo governo.

No Brasil, a Previdência Social é composta por três instituições: Ministério da Previdência Social - MPS; Instituto Nacional de Seguro Social - INSS e Empresa de Tecnologia e Informações da Previdência Social - Dataprev. Cabe a essas organizações, em conjunto, gerenciar o sistema de previdência brasileiro, supervisionando e normatizando a previdência dos regimes próprios dos servidores, bem como a previdência complementar fechada, e garantir o funcionamento do Regime Geral de Previdência.

O INSS tem como responsabilidade adicional reconhecer direitos, conceder e proceder ao pagamento mensal dos benefícios da Lei Orgânica da Assistência Social - LOAS. A Dataprev é responsável pelo processamento da maior folha de pagamento do País, alcançando mais de 20 milhões de beneficiários. Além disso, tem contribuído para a informatização dos diversos órgãos previdenciários, modernizando os serviços prestados, a fim de que o segurado receba um atendimento de melhor qualidade (BrasiL, 2003).

O Portal da Previdência Social ${ }^{12}$, criado no ano de 1997, disponibiliza hoje uma série de funcionalidades, entre as quais se destacam:

- Serviços: atualização de endereço; autorização de débito automático em conta; baixa de empresa; cadastramento de obras; canal de comunicação; comunicação de acidente de trabalho e inscrição na Previdência Social;

- Requerimentos: auxílio-doença; perícia médica; consulta às perícias agendadas; marcação de exame médico pericial para fins de reexame de auxíliodoença; requerimento de pedido de prorrogação e reconsideração; auxílio-doença para empresa convenente; saláriomaternidade; pensão por morte; e

- Consultas: andamento de processos; cálculo de aposentadoria; carta de concessão e memória de cálculo do benefício; censo previdenciário; certidões de tempo de contribuição e para saque do PIS/PASEP/FGTS; consulta a benefícios por incapacidade por empresa; consulta às inscrições do trabalhador; consulta às perícias agendadas; consulta integrada às informações do trabalhador; empréstimo consignado; extratos de pagamentos de benefícios e para imposto de renda; documentos solicitados para requerer benefícios; formulários solicitados para requerer benefícios; perfil profissiográfico previdenciário; precatórios; revisão de benefícios; sistema para cadastramento e atualização de dados de óbitos pelos Cartórios de Registro; baixa de arquivos de óbitos para entidades; tabelas de pagamento de benefício e de reajuste de benefício; arquivos digitais para auditoria fiscal de empresas; cálculo de contribuição. 
A possibilidade de acesso à série de serviços da Previdência Social, por meio $\mathrm{da}$ internet, influi diretamente na governança do setor público, levando ao seu aperfeiçoamento em várias dimensões: progresso da cidadania e da igualdade; desenvolvimento da efetividade governamental, pela provisão de serviços de melhor qualidade, caracterizados por sua simplicidade e rapidez. Todos esses fatores culminam no crescimento da responsividade e da eficiência do governo e na facilitação de resultados que enriquecem a qualidade de vida dos habitantes.

A eficácia das iniciativas de governo eletrônico vistas até agora como propulsoras da governança do setor público, ficam na dependência do grau de inclusão digital da população brasileira.

A taxa de usuários da internet está crescendo rapidamente: de 3\% da população mundial, em 1995, para 11\% em 2003 (600 milhões de pessoas). Entretanto, há uma forte possibilidade desse incremento estagnar em torno dos $20 \%$, reproduzindo a "sociedade de um quinto", na qual $20 \%$ da população mundial monopoliza $80 \%$ dos recursos do planeta (Unesco, 2005).

Tal cenário pode ser verificado quando se comparam nações ricas e pobres, mas também quando se analisa a realidade dentro de um único país, ainda que integrante do primeiro grupo. Richard Groper (2004) fez uma pesquisa nos Estados Unidos, a qual explicita a forte correlação entre as taxas de acesso à internet e outros fatores, como renda e nível educacional, evidenciando a divisão digital naquela região.

A emergente Sociedade da Informação somente encontra sua razão de ser quando alcança o objetivo de construir Sociedades do Conhecimento, que são fonte de desenvolvimento para todos, principalmente para os países menos desenvolvidos (UNESCO, 2005).

A capacidade de acessar, adaptar e criar novo conhecimento por meio das TIC é decisiva para o processo efetivo de inclusão social (WARSCHAUER, 2006).

A internet possui uma variedade de características que promovem o engajamento dos cidadãos: interatividade; acessibilidade; baixo custo e capacidade
“A contribuição da votação eletrônica para o reforço da governança do setor público dá-se pela solidificação da democracia, da cidadania, da igualdade, da voz e da representação (...)”

de disseminação de grande volume de informação rapidamente (SMITH; SMYTHE, 2004).

No Brasil, existe hoje uma série de ações governamentais para inclusão digital, conduzidas de maneira descentralizada pelos diversos ministérios, sem uma coordenação geral (NAZARENO et al., 2007):

- Programa Sociedade da Informação - Socinfo ${ }^{13}$ 
- Programa Nacional de Informática na Educação - Proinfo ${ }^{14}$;

- Governo Eletrônico Serviço de Atendimento ao Cidadão - Gesac ${ }^{15}$;

- Computador para Todosic;

- Espaço Serpro Cidadão ${ }^{17}$;

Há, ainda, um rol de ações do Governo Federal para infoinclusão em fase de implantação (NAZARENo et al., 2007):

- Casa Brasili

- Projeto Computadores para Inclusão ${ }^{19}$;

- Programa Nacional de Cultura, Educação e Cidadania - Cultura Viva ${ }^{20}$;

- Programa de Telecentros de Informação e Negócios ${ }^{21}$;

- Centros Vocacionais Tecnológicos ${ }^{22}$;

- Programa Freqüência Digital ${ }^{23}$;

- Observatório Nacional de Inclusão Digital - ONID ${ }^{24}$; e

- Projeto Maré - Telecentro da Pesca ${ }^{25}$;

- Programa de Inclusão Digital do Banco do Brasil ${ }^{26,27}$;

- Projeto Quiosque do Cidadão ${ }^{28}$; e

- Centros Rurais de Inclusão Digital CRIDs $^{29}$

Apesar dessas ações, o último levantamento realizado no Brasil mostra que 79\% da população, com 10 anos ou mais de idade, não acessou a internet nos últimos três meses (IBGE, 2007).

Essa situação repete o panorama mundial, pois o acesso varia significativamente de acordo com a renda e a escolaridade. No maior extremo de renda pesquisado (domicílios com renda mensal per capita superior a 5 salários mínimos), $69,5 \%$ dos brasileiros usavam a rede. No extremo oposto (renda mensal per capita inferior a um quarto do salário mínimo), esse mesmo percentual era de apenas 3\% (IBGE, 2007).

$\mathrm{O}$ acesso cresce em função da renda, mas mesmo em faixas intermediárias, como a de 2 a 3 salários mínimos per capita, ele ainda é restrito a uma minoria (42\%). $\mathrm{O}$ mesmo fenômeno constata-se quando é avaliado o acesso de acordo com grau de escolaridade. No extremo de menor instrução (menos de 4 anos de estudo), somente $2,5 \%$ acessavam a internet. No extremo oposto (os que completaram ao menos o ensino médio), essa proporção alcança 76,2\% do total (IBGE, 2007).

\section{Conclusão}

Inovações tecnológicas recentes propiciaram moldar as relações da sociedade com seus governos de forma inédita, com maior interatividade, participação e simplicidade. Neste trabalho foram catalogadas e descritas algumas ações do Governo Federal no Brasil, atuando positivamente em prol do fortalecimento da governança do setor público.

A certificação digital, método fundamental para garantir a segurança das informações eletrônicas, mostrou-se como ação indutora da governança do setor público, atuando nas dimensões de garantia da inviolabilidade e da consolidação da cidadania; apoio ao mercado e melhoria da eficiência e da qualidade regulatória.

O Portal da Transparência, importante canal de acesso do cidadão acerca de gastos do governo, contribui com a disponibilização de informações à sociedade, aumentando a transparência e a responsabilização, favorecendo um maior controle da corrupção e melhorando a cidadania.

A informatização dos pleitos eleitorais, atualmente abrangendo todas as votações realizadas no País, atua efetivamente na consolidação da democracia, da cidadania, da igualdade, da voz e da representação, além de promover ganhos de eficiência e transparência ao processo como um todo. 
O pregão eletrônico, instrumento que merece consideração por seu uso disseminado nas compras governamentais, tem efeito positivo nas dimensões da eficiência, ampliando-a pela automação de sistemas e processos administrativos, e de apoio ao mercado, proporcionando a participação de um maior número de empresas concorrentes nos certames.

O Portal da Previdência Social, copiosa evolução na informatização da prestação de serviços, disponibiliza uma série de funcionalidades que melhoram a responsividade, a eficiência e a efetividade governamental, pelo atendimento virtual aos usuários, facilitando resultados que enriquecem a qualidade de vida dos residentes e aperfeiçoando a cidadania e a igualdade.
Apesar dos avanços recentes no sentido de aprimorar a governança do setor público, ainda há muito o que fazer em direção à inclusão social no Brasil, assim como em outros países, consoante diversos levantamentos dados a conhecer na seção anterior. A oferta eletrônica de serviços públicos e de informações aos cidadãos tem sua eficácia condicionada à efetividade das políticas públicas de infoinclusão.

As TIC podem vir a ser um poderoso agente de inclusão digital, apoiando a governança com a criação de espaços virtuais para participação democrática e diálogo cívico e com a expansão desta em tomada de decisão coletiva, promovendo a igualdade e a cidadania.

(Artigo recebido em 18 de dezembro de 2007. Versão final em 18 de março de 2008).

\section{Notas}

${ }^{1}$ Decreto no 3.294, de 15 de dezembro de 1999.

${ }^{2}$ Decreto de 18 de outubro de 2000.

${ }^{3}$ http:/ / www.governoeletronico. gov.br

${ }^{4}$ Decreto de 29 de outubro de 2003.

${ }^{5}$ Decreto no ${ }^{\circ} .901$, de 26 de novembro de 2003.

${ }^{6}$ Decreto no 5.820 , de 29 de junho de 2006.

${ }^{7}$ Medida Provisória no 2.200-2, de 24 de agosto de 2001.

${ }^{8}$ http://www.portaldatransparencia. gov.br

${ }^{9}$ Lei no 10.520 , de 17 de julho de 2002.

${ }^{10}$ Decreto $^{\circ}{ }^{5} .450$, de 31 de maio de 2005.

${ }^{11}$ http://www.comprasnet.gov.br

12 http://www.previdencia.gov.br

${ }^{13}$ http://ftp.mct.gov.br/Temas/Socinfo/default.asp

${ }^{14}$ http://www.proinfo.mec.gov.br

${ }^{15}$ http://www.idbrasil.gov.br

${ }^{16}$ http://www.computadorparatodos. gov.br

17 http://www.serpro.gov.br/cidadao

18 http://www.iti.gov.br 
${ }^{19}$ https://www. governoeletronico. gov.br/acoes-e-projetos/computadores-para-inclusao

${ }^{20} \mathrm{http}: / /$ www.cultura.gov.br/programas_e_acoes/cultura_viva/programa_cultura_viva

21 http://www.telecentros. desenvolvimento.gov.br/sitio/inicial/index.php

${ }^{22}$ http://www.mct.gov.br/index. php/content/view/11483.html

${ }^{23}$ http://www.serpro.gov.br/arq01.pps

${ }^{24}$ http://www.inclusaodigital.gov.br/inclusao/onid

25 http://200.198.202.145/seap/telecentro

${ }^{26} \mathrm{http}: / /$ www.fbb.org.br/estacaodigital/pages/publico/index.jsp

27 http://www44.bb.com.br/appbb/portal/bb/id/index.jsp

${ }^{28} \mathrm{http}: / /$ www.integracao.gov.br/comunicacao/noticias/noticia. asp?id=1687

${ }^{29} \mathrm{http}: / /$ inclusao.ibict.br/index.php?option=com_content\&task=view\&id=630\&Itemid=298

\section{Referências bibliográficas}

Australian Government. Foundations of governance in the australian public service. Canberra: Australian Public Service Commission, 2007.

Brasil. Glossário icp brasil. Brasília: Infra-Estrutura de Chaves Públicas Brasileira, 2007a. . Relatório de gestão: eleições 2006. Brasília: Tribunal Superior Eleitoral, 2007b. - Relatório de gestão 2003. Brasilia: Ministério da Previdência Social, 2003. . Sociedade da informação no Brasil: livro verde. Brasília: Ministério da Ciência e

Tecnologia, 2000.

European Communities. The role of egovernment for europe's future. Brussels: Commission of the European Communities, 2003.

Groper, R. Digital government and the digital divide. In: Pavlichev, A.; Garson, G. D. (Orgs.). Digital government: principles and best practices. Hershey: Idea Group Publishing, 2004. Instituto Brasileiro de Geografia e Estatística. Pesquisa nacional por amostra de domicílios 2005: acesso à internet e posse de telefone móvel celular para uso pessoal. Rio de Janeiro: Diretoria de Pesquisas, Coordenação de Trabalho e Rendimento, 2007.

Kaufmann, D.; KraAY, A.; MAstruZZI, M. Governance matters vi: aggregate and individual governance indicators 1996-2006. World Bank Policy Research Working Paper 4280, July 2007.

LÉvy, P. Ciberdemocracia. Lisboa: Instituto Piaget, 2004.

National Audit Office. Better Public Services through e-government. London: The Stationery Office, 2002.

NaZAreno, C. et al. Tecnologias da informação e sociedade: o panorama brasileiro. Brasília: Câmara dos Deputados, 2007.

Office for Public Management Ltd; The Chartered Institute of Public Finance AND AcCountancy. The good governance standard for public services. London: The Independent Commission for Good Governance in Public Services, 2004. 
Organization for Economic Co-operation and Development. Modernising government: the way forward. Paris: OECD Publishing, 2005.

Publishing, 2003.

. OECD E-government studies - the e-government imperative. Paris: OECD

SHAH, A.; SHAH, S. The new vision of local governance and the evolving roles of local governments. Washington, DC: World Bank, 2006.

Sмith, P. J.; Smythe, E. Globalization, citizenship and new information technologies: from the MAi to seattle. In: Mälkiä, M.; Anttiroiko, A.; Savolainen, R. (Orgs.). eTransformation in governance: new directions in government and politics. Hershey: Idea Group Publishing, 2004.

THE WORLD BANK. Reforming public institutions and strengthening governance: a world bank strategy. Washington, DC: World Bank, 2000.

United NATIONs. Unlocking the human potential for public sectorperformance. World Public Sector Report 2005. New York: Department of Economic and Social Affairs, 2005.

United Nations; American Society for Public Administration. Benchmarking egovernment: a global perspective. New York: Division for Public Economics and Public Administration, 2002.

United Nations Educational, Scientific and Cultural Organization. Towards knowledge societies. Paris: UNESCO Publishing, 2005.

Warschauer, M. Tecnologia e inclusão social: a exclusão digital em debate. São Paulo, SENAC, 2006. 


\section{Resumo-Resumen-Abstract}

\section{O Papel do Governo Eletrônico no Fortalecimento da Governança do Setor Público}

Lamartine Vieira Braga, Welington Souza Alves, Rejane Maria da Costa Figueiredo e Rildo Ribeiro dos Santos

As novas Tecnologias da Informação e Comunicação (TIC), entre as quais se destacam a internet, as redes de computadores, a transmissão via satélite e a telefonia móvel, criaram condições para o surgimento de Sociedades do Conhecimento. Nesse contexto, o Estado, por intermédio do governo eletrônico, é o principal instrumento de que os cidadãos dispõem atualmente para enfrentar os desafios impostos pela globalização, por meio de interações inéditas da sociedade, empresas e governos. O objetivo deste trabalho foi estabelecer relações entre a governança do setor público e o governo eletrônico, partindo-se de um marco referencial teórico das duas áreas de estudo. Para tanto, foram delineados seus escopos e limites de atuação, instituindo-se vínculos, de acordo com ações do Governo Eletrônico brasileiro: certificação digital; Portal da Transparência; votação eletrônica; pregões eletrônicos e Portal da Previdência Social. Conclui-se que, apesar dos avanços recentes observados pela análise de várias dimensões da governança, baseados em iniciativas de governo eletrônico aqui inventariadas, ainda há muito que fazer em direção à inclusão social no Brasil, assim como em outros países. As TIC podem vir a ser um poderoso agente de inclusão digital, apoiando a governança com a criação de espaços virtuais para participação democrática e diálogo cívico e expansão da participação em tomada de decisão coletiva, promovendo a igualdade e a cidadania.

Palavras-chave: governo eletrônico; governança do setor público; administração pública

\section{El papel del gobierno electrónico en el fortalecimiento de la gestión de los asuntos públicos \\ Lamartine Vieira Braga, Welington Souza Alves, Rejane Maria da Costa Figueiredo y Rildo Ribeiro dos Santos}

Las nuevas Tecnologías de Información y Comunicación (TIC), entre las que se destacan la internet, redes de computadoras, la transmisión por satélite y la telefonía móvil, crearon las condiciones para el surgimiento de las sociedades del conocimiento. En este contexto, el Estado, a través del gobierno electrónico, es el instrumento principal que la gente tiene ahora para hacerse cargo de los retos impuestos por la globalización, sin precedentes a través de las interacciones entre la sociedad, las empresas y los gobiernos. El objetivo de este trabajo fue establecer las relaciones entre la gestión del sector público y el gobierno electrónico, a partir de un marco teórico de referencia de estas dos áreas de estudio. Para ello, se esbozaron sus alcances y los límites de actuación, y se establecieron sus vínculos en conformidad con acciones del Gobierno Electrónico brasileño: la certificación digital; el portal de transparencia; la votación electrónica; las subastas electrónicas y el portal de la Seguridad Social. De ello se deduce que, a pesar de los recientes avances vistos por el análisis de diversos aspectos de la gestión pública, basados en las iniciativas de gobierno electrónico inventariadas aquí, todavía queda mucho por hacer hacia la inclusión social en Brasil, así como en otros países. Las TIC pueden tornarse un poderoso agente de inclusión digital apoyando a la gestión de los asuntos públicos con la creación de espacios virtuales para la participación democrática, el diálogo cívico y la expansión de la participación en la toma de decisiones colectivas y promoviendo la igualdad y la ciudadanía.

Palabras-clave: gobierno electrónico; gestión de los asuntos públicos; administración pública 
The role of e-government in strengthening public sector governance

Lamartine Vieira Braga, Welington Souza Alves, Rejane Maria da Costa Figueiredo and Rildo Ribeiro dos Santos

The new Information and Communication Technologies (ICT), like the internet, networks of computers, satellite transmission and mobile telephony, have created conditions for the emergence of Knowledge Societies. At this context, the State, through e-government, is the main instrument that people have now to face the challenges imposed by globalization, by way of unprecedented interactions among society, business and governments. This article aims to establish links between public sector governance and electronic government, from the theoretical referential landmark of those two great areas of study. After their purposes and limits of performance have been well delineated, its correlations are evidenced during the exposition of Brazilian electronic government actions: digital certification; transparency web site; electronic voting; electronic governmental purchases; and Social Welfare web site. In conclusion, notwithstanding the recent advances observed by the analysis of many dimensions of governance, based on initiatives of electronic government listed here, there is still a lot to do toward social inclusion in Brazil, as in other countries. ICT can be a powerful agent of digital inclusion by supporting the governance by the means of creation of virtual space for democratic participation and civic dialogue and expansion of taking part in collective decision-making, promoting equality and citizenship.

Keywords: e-government; public sector governance; public administration

Lamartine Vieira Braga

Mestrando em Gestão do Conhecimento e da Tecnologia da Informação pela Universidade Católica de Brasília; Especialista em Administração Pública pela EBAPE/FGV; Especialista em Políticas Públicas e Gestão Governamental pela ENAP.

Contato: lamartine.braga@planejamento.gov.br

Welington Souza Alves

Mestrando em Gestão do Conhecimento e da Tecnologia da Informação pela Universidade Católica de Brasília; MBA em Gestão Empresarial pela UniDF; Certificado PMP.

Contato: walves@tycon.com.br

Rejane Maria da Costa Figueiredo

Doutora em Engenharia Mecânica pela EESC/USP; Professora do Mestrado em Gestão do Conhecimento e da Tecnologia da Informação da Universidade Católica de Brasília.

Contato: rejane@ucb.br

Rildo Ribeiro dos Santos

Doutor em Cências Física Aplicada e Computacional pela USP; Professor do Mestrado em Gestão do Conhecimento e da Tecnologia da Informação da Universidade Católica de Brasília.

Contato: rildo@ucb.br 


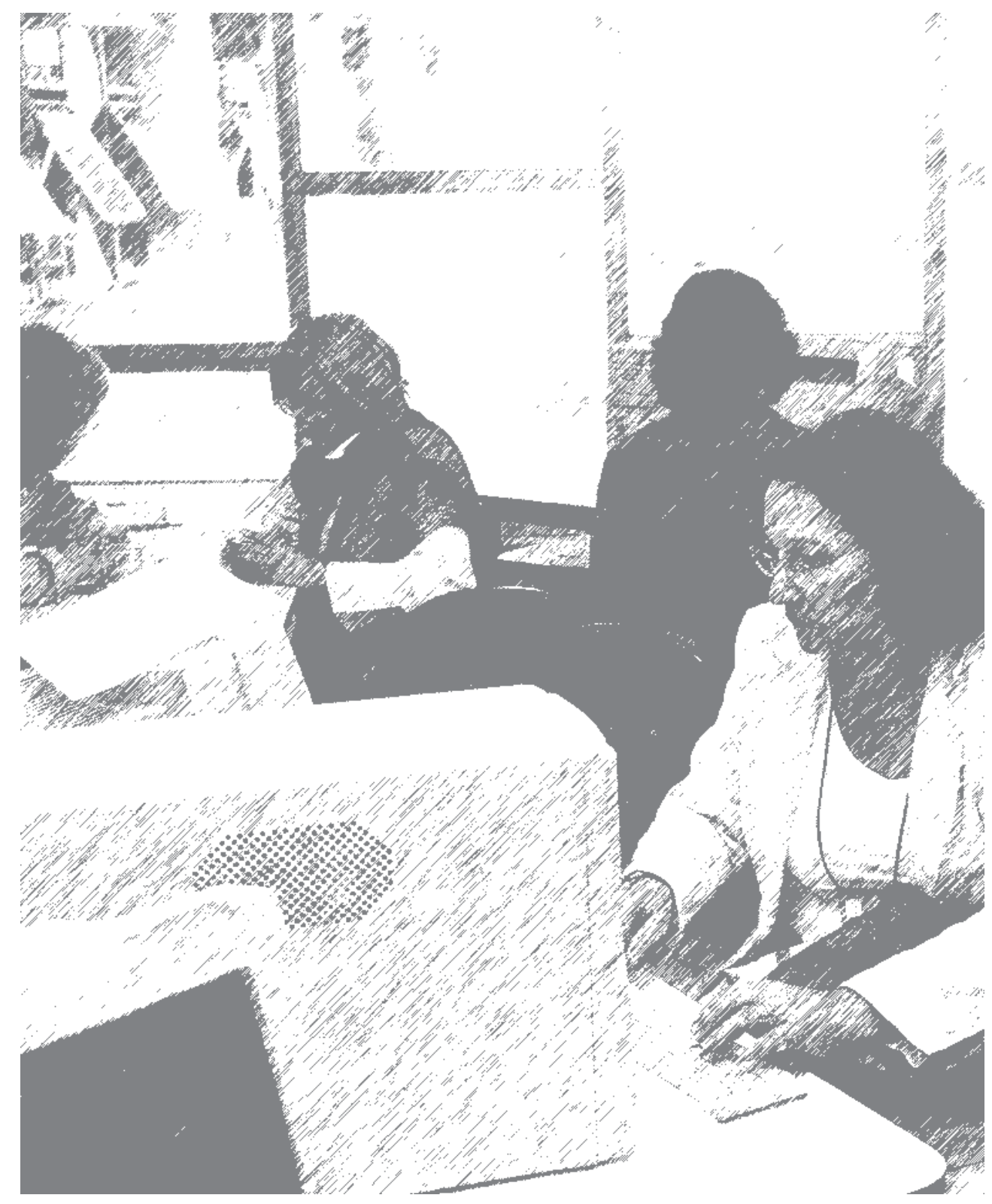

